\title{
A Survey on the Interfacing the Wireless Sensor Networks with the Cloud
}

\author{
Asha K. R. \\ Asst. Professor \\ Sri Siddhartha Institute of Technology \\ Tumkur
}

\author{
K. Suresh, PhD \\ Principal \\ Sri Dharmasthala Manjunatheshwara Institute of \\ Technology, Ujire
}

\begin{abstract}
Informative, complex and a lot of data from different situations are sensed by different sensors in wireless sensor network and are being uploaded into cloud for getting good storage and transfer the well processed data to the physical world in an efficient manner. Hence, there is a need for interfacing Wireless sensor Network with the cloud, by choosing different communication protocols and appropriate wireless technology, to cover wide area and to provide services for the diverse requirements. In this paper, surveyed several approaches used to upload sensed data from sensor in wireless sensor network into the cloud in an efficient manner by using communication protocols and wireless technologies by assessing their key technical concepts and different parameters.
\end{abstract}

\section{Keywords}

Cloud, Wireless Sensor Network, Wireless Technologies, Communication protocols

\section{INTRODUCTION}

Collection of extraordinary sensors with an intercommunication framework establishes to a Wireless Sensor Network, for sensing and observing situation at varied regions. Sensors which produce electrical signals depending on sensed physical parameters and circumstances observed. [1] Generally monitored parameters are pressure, speed, humidity, temperature, wind direction, power line, voltage, chemical concentrations pollutants levels, emission counts of radiation, vital body functions, intensity of sound, vibration and illumination. However, the sensing nodes in a network are deployed densely and prone to failures. They have higher orders of magnitude and use broadcast communication paradigm. They may not have global identification (ID) due to large amount of overhead and limited in power, computational capacities and memory. Topologies of a sensor network changes very frequently because of large number of sensors.

Wireless sensor networks are needed because, [2]

- There is no need of any fixed infrastructure for setting up the network.

- It is suitable for non-reachable areas like deep forests, mountains, rural areas, sea and radiation leakage area.

- It is very much flexible in extending the workstation when it is needed.

- Reduce cost of implementation.

- It avoids risk involved in wiring

- New devices can be included in the network whenever it is needed.
- Partitions can be done with ease.

- Centralized system can access the information by the network

Wireless Sensor Network has come up with magnificent tool for different areas of application. Sensors are classified into Environmental sensors, Gas sensors, Physical sensors, Optical and Biometric sensors. Environmental sensors are used in the area of agriculture for finding quality of water, temperature, soil humidity, wind speed and wind direction. Gas sensors are used to find Organic gas Carbon evolved from the living system. Physical sensors are used for finding movement of any object in living system. Optical sensors are used to find human presence through the IR spectrum and to find total amount of energy and light absorbed by plant by finding absorption of sun light, radiation and ultraviolet rays. By identifying radiation leakage in the area, it avoids human life from dangerous causes. Biometric sensors like accelerometer avoid probable attacks or the fall of person who are suffering from heart problems by observing the pulse and activities of heart and alert the related persons by SMS alarms that uses the GSM/GPRS module.

Along with these WSN applications are found in Natural environment protection, Area monitoring, Supplies control in manufacturing, Radiation prevention, Disaster relief operations, Earth quake detections, Biodiversity mapping, Intelligent buildings or bridges, Industrial automation, Machine surveillance and preventive maintenance, Tanks and oil level control, Medicine and health care, Traffic monitoring, Electric consumption, Precision agriculture, Irrigation, consumption of water, detection of leakages in pipe lines, Liquid storage management and Animal grazing, etc.

In spite of this, WSNs have to face many problems with regards to the range of short communication, security and privacy, reliability, mobility, consideration of power, capacity of storage, capabilities of processing and availability of bandwidth. At the side, wireless sensor network contains its components and specific constraints in design, depending on the area under monitor. Whatever it may be, by the availability of wireless technologies and communication protocols all these problems can be overcome by integrating the objects instead of people, to create a smart environment to upload the sensed data from WSNs to cloud.

In this paper, overview of wireless sensor network and its application is illustrated. The remaining part of the paper is organized into different sections: Section II presents existing literature survey, Section III presents survey of various wireless technologies for interfacing WSNs with cloud and Section IV concludes the paper by summarizing the overall study. 


\section{EXISTING LITERATURE}

Rajeev Piyaree and Seong Ro Lee [3] proposed the architecture for integrating wireless sensor Networks with the cloud for sharing sensor data. To get an inter-operable application layer, this is directly integrated into other application domains for remote monitoring such as health care services, smart homes, and vehicular area network. For that, they have used representational state transfer based web services and implemented different decision levels for different architectural layers.

There is a need of better web services, wireless standards, modules and mechanism to build a low power, deployment of nodes in a simple manner, reliable data transmission-self healing wireless sensor network, to decrease energy consumption and to increase the life time of network devices.

Gathri. K and v. Ananthanarayan [4] presented a frame work for integration of WSNs with cloud. Data from all the deployed sensors is aggregated in to single message and sent to the cloud for storing. There is a lack in minimizing the path to send the data to the base station. New concept of algorithm is needed for that.

Khandakar Entenam Unayes Ahamed and Mark A Gregory [5] proposed an infrastructure to integrate the cloud computing model with WSN. This framework gives approaches for managing user, access control, and storage of data. Sensed data form sensor in WSN goes to data repository and data processing unit through gateway. Unnecessary data will be processed for trimming. The formatted data is sent to the data repository for storage. Data along with index stored in publish/subscribe broker. Subscription will be created by Request Subscriber. Whenever the data is requested Event Matcher will find map between subscription requests and published data. Then mapping is over. Publish/subscribe broker will fetch data from data repository and allow the data to user through cloud's user interface.

However there is need of development of methodology for data processing, storage and retrieval of data.

Peng Zhang et al., [6] proposed an architecture by integrating WSNs with cloud. Here, a cloud acts as a virtual sink and collects sensing data from different points and for processing collected data, processing software is used in the cloud. WSNs are divided into zones. Size of sensors is reasonable, then sink will send by the commands to sensor nodes. Master/slave architecture is used in data processing system, in which master is responsible for storing data. Band width cost is reduced by comprising data with the help of compression mechanism called Hadop. Master node is connected to the internet and is the access point.

Chunsheng Zhu et al., [7] focused on integrating WSNs and mobile cloud computing. Here, sensors in WSN collect the data and give it to cloud. From the cloud mobile user will use the data. For the cloud, source is WSN and the data requester to cloud is mobile user. Here TPSS Scheme is used for integrating WSN with mobile cloud. It includes Time and Priority-based Selective Data Transmission for Wireless sensor networks gateway to transmit selected sensed information to cloud and priority -based sleep scheduling algorithm for Wireless sensor network to minimize the energy utilization so that it can collect and transmit.

Javier Barbaran and Manuel Diaz Bartoome Rubio [8] presented a frame work for integrating wireless sensor in the cloud. The basic idea of the framework is the concept of virtual channels which define communication between physical and virtual sensors. Those channels exchange messages between the virtual sensors and the cloud with less complexity, less computing and less battery utilization.

Sajid Hussian Shah et al., [9] proposed architecture that integrates a wireless sensor network to the internet using cloud. Long range destination is communicated by using short range communications protocol.

There is need of more security in integration of wireless sensor network to the internet using cloud which is very much essential for focus on critical issues.

Samer samarah [10] proposed a prediction model for integrating wireless sensor networks and cloud. The purpose of data prediction model is to send fine detailed summarized data to data centric center's by minimizing extra load on the sensors nodes for improving the performance of WSNs through reducing the lot of data to be sent to the cloud system.

However still there is need of several predication models to improve the performance of the WSNs when integrating with cloud.

Sanjit Kumar Dash et al., [11] surveyed applications of WSNs and cloud computing and discussed some issues of cloud computing and sensors network, to get single virtual wireless sensor network through cloud computing by combing WSNs of different applications under one roof.

Sanjit Kumar et al., [12] investigated the design and challenges for sensor clouds and proposed a framework for integration of sensor cloud. The idea in their frame work is WSNs of different applications are combined together as single through cloud considering it has distinct virtual WSN.

However, the success of the sensor cloud mainly depends on the capability of the sensor network and cloud, increasing the compatibility in the techniques and algorithm.

Nathalie Milton et al., [13] presented an architecture using which sensed data of different environment can be accessed by the different users for their requirements. Design of pervasive infrastructure contains Hypervisor, Autonomic Enforcer and Volunteer Cloud manager components. Hypervisor duty is to broadcast command, retrieve the data from the standalone sensors or from WSNs, abstraction of devices which are connected and virtualization of abstracted resources. Sensing devices are communicated with the help of adapter. Communication between nodes and cloud is by the Autonomic Enforcer. Volunteer Cloud manager centralized the sensors in a cloud Environment.

There is a need of high level of abstraction of sensing technologies and addressing the volatility of mobiles through volunteer based techniques.

Manuel et al., [14] surveyed different components for integration of different levels, analyzed different existing proposals, identified some challenges and research issues. They also presented survey on platforms and infrastructures needed for cloud, middleware for internet of things, and data analytics techniques for integration of internet of things with cloud computing.

Zhengguo Sheng et al., [15] proposed an approach for Management of Wireless sensor networks and COAP based management protocol to connect sensor devices through cloud for construction of prototype system.

There is need of efficient design of gateway to get better service and middleware design to transfer information when a sensed data is out of threshold. 


\section{SURVEY OF VARIOUS WIRELESS TECHNOLOGIES FOR INTERFACING WIRELESS SENSOR NETWORKS WITH CLOUD COMPUTING}

In real world environment, to get more services from wireless technology to the users for different applications, single technology cannot possess properties like fast range of operation, maximum data rate, vast area of coverage, high level of security, safety, scalability and reliability. Users are also expecting systems like cheap and consume less power from wireless technologies devices. Hence they are classified by different parameters such as number of channels, frequency bands and access and modulation techniques,[16] etc. Some application in environment needs significant improvement in identification and monitoring by covering wider area. The use of better technology in combination with WSN and cloud gives the promising future for sensing data from sensors in WSN by identifying the situation properly and upload the data for cloud in efficient manner.

Table 1 Shows power consumption of short, medium and long range wireless technologies. Fig 1 shows the pictorial representation of power consumption of short, medium and long range wireless technologies. Table 2 Provide data rate comparisons among different range of wireless technologies and Fig 2 shows pictorial representation of Data rate of short, medium and long range wireless technologies Table 3: shows Survey of various Wireless Technologies for interfacing Wireless sensor networks with cloud computing and also Shows appropriate wireless technology cover wide area and to provide various services services for the diverse requirements.

By observing the figure.1 power consumed by long range wireless technology is high and figure. 2 shows the data rate comparison of short, medium and long range wireless technologies. It is observed that, for the application of internet access WIFI is suitable because it gives high data rate. However, for monitoring and controlling, ZigBee and Bluetooth are better technologies. RFID is an effective identification technology and cellular technologies such as GSM, GPRS and UMLTS provides low data rates. WiMAX provides high data rate for long range communication. Hence, for interfacing Wireless sensor with cloud for uploading sensed data in reliable, secure, seamless communication manner, there is a need of selecting suitable wireless technology.

\section{CONCLUSION}

In this paper we have reviewed several papers which have integrated Wireless sensor network with cloud for uploading the sensed data from the sensors in a network in an efficient way to the cloud by using different technologies. Many of the existing works from different authors are widely reviewed which makes it possible for many of the users to have a direct conclusion about the technology that can be used for the specified application. Here selection of technology depends on different parameters based on limited consumption of power, desire range, well architecture, network span, security, suitable band width and number of channels. Hence it allows the user to select better technology. Different communication protocols and appropriate wireless technology cover wide area and to provide services for the diverse requirements. By the availability of wireless technologies and communication protocols all communication problems can be overcome by integrating the objects instead of people, to create a smart environment to upload the sensed data from WSNs to cloud.

\section{REFERENCES}

[1] I.F.Akyildiz, W.Su, Sankara, Subramaniam, E.Cayirci "Wireless Sensor Networks: A Survey" Elsevier Science B.V, pp: 394-422, December 2001.

[2] Prashant Tiwari, Varun Prakash Saxena, Raj GavravMishra, Devendra Bhavsar Mishra,"Wireless Sensor Networks: Introduction, Advantages, Applicaons and Research Challenges", HCTL open international journals of Technology innovations and Research, pp: 2321-1814, vol14, April 2015.

[3] Rajeev Piyare, Seong Ro Lee,"Towards Internet of Things (IOTs): Integration of Wireless Sensor Network to cloud Services for Data Collection and Sharing", International Journal of computer Networks and Communication (IJCNC), Vol 5, No 5, pp: 59-72, September 2013.

[4] Gayathri K, V. Ananthanarayanan," Design of Several and Efficient Wireless Sensor Network with Integration to Public Cloud for Big Data Analytics", International Journal of Recent development in Engineering and Technology, Vol 3, IJRDET, pp: 190-196, July 2014.

[5] Khandakar Entenamunayes Ahamedand Mark A Geogory,"Integrating Wireless Sensor Networks With Cloud computing", Seventh International Conference on Mobile Ad-hoc and Sensor Networks, MSN 2011, Beijing, China, December 16-18, 2011.

[6] Peng Zhang, Zheng Yan, Hanlin sun,"A Novel Architecture Based on cloud computing for Wireless Sensor Network", Proceedings of the 2nd International conference on Computer Science and Electronics Engineering (ICCSEE 2013).

[7] ChungshengZhu, Zhengguo Sheng, victor.M.Leung, Lei Shu and Laurence.T.Yang, Toward Offering More useful Data Reliably to Mobile Cloud from Wireless Sensor Network, IEEE Trans, Emerging Topics In computing, Vol 3, No 1, pp: 84-94, March 2015.

[8] Javier Barbaran, Manuel Diaz, Bartolome Rubio,” A Virtual Channel-based Framework for the Integration of Wireless Sensor Networks in the Cloud", IEEE, Future Internet of things and Cloud (FiCloud), pp: 334-339, 2014/8/27.

[9] Sajjad Hussian Shah, Asad Iqbal, Fazle Kabeer Khan,Wajid Ali, "A New Framework to Integrate Wireless Sensor Networks with Cloud Computing", IEEE, Aerospace Conference, 2013.

[10] Samer Samarah,"A Data Predication model for Integrating Wireless Sensor Networks and Cloud computing", Elsevier B.V, pp: 1141-1146, May 2015.

[11] Sanjit Kumar Dash, Subasish Mohapatra, Prasant Kumar Pattnaik, "A Survey on Applications of Wireless sensor Network using cloud Computing", International Journal of computer Science and Emerging Technologies, Vol1,PP:50-55,December 2010.

[12] Sanjit Kumar Dash, Jyothi Prakash Sahoo, Subasis Mohapatra, Sarada Prasanhapati, "Sensor Cloud: Assimilation of Wireless Sensor Network and the cloud", CCSIT, Part I, LNICST 84, PP:455-464, 2012.

[13] Nathalie Mitton, Symeon Papavassilliou, Antonio 
Pulicyito, Kishor S. Trivedi, "Combining cloud and Sensors in a smart city environment", EURASIP Journal on Wireless Communications and Networking, http://jis.eurasipjournals.comcontent/2012/1/247, 2012.

[14] Manuel Diaz, Cristian Martin, Bartolome Rudio, "Stateof-the art, challenges and Open issues in the integration of internet of Things and Cloud Computing, Elsevier, PP: 99-117, 2016.

[15] Zhengguo Sheng, ChinmayaMahapatra, Chunsheng Zhu and Victor C.M Leung, Recent Advances in Industrial
Wireless Sensor Networks Toward Efficient Management in IOT, IEEE ACCESS, Vol 3, pp: 622-637 June 2015.

[16] Mulla, Afshan, JaypalBaviskar, Smith Khareand Faruk Kazi,"The wireless Technologies for Smart Grid Communication: A Review", 2015 Fifth International Conference on Communication Systems and Network Technologies, 2015.

\section{APPENDIX}

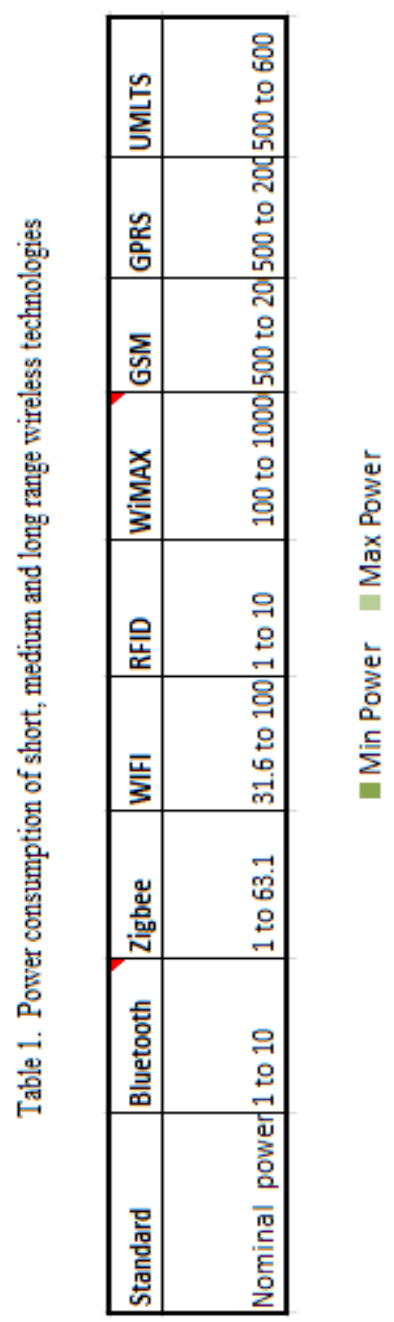

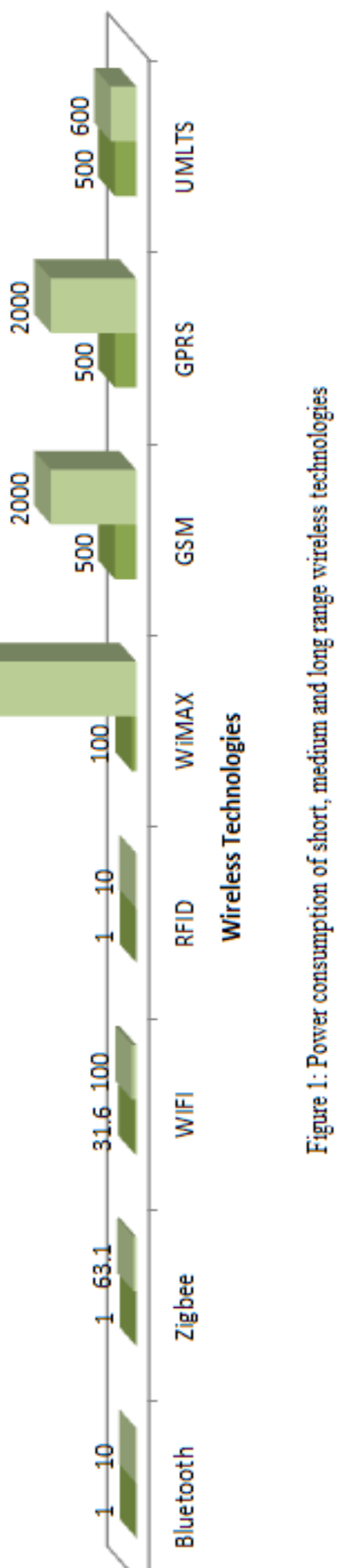

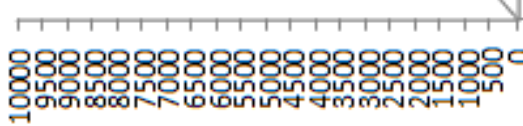

(mu) uongdunsuog dannod 

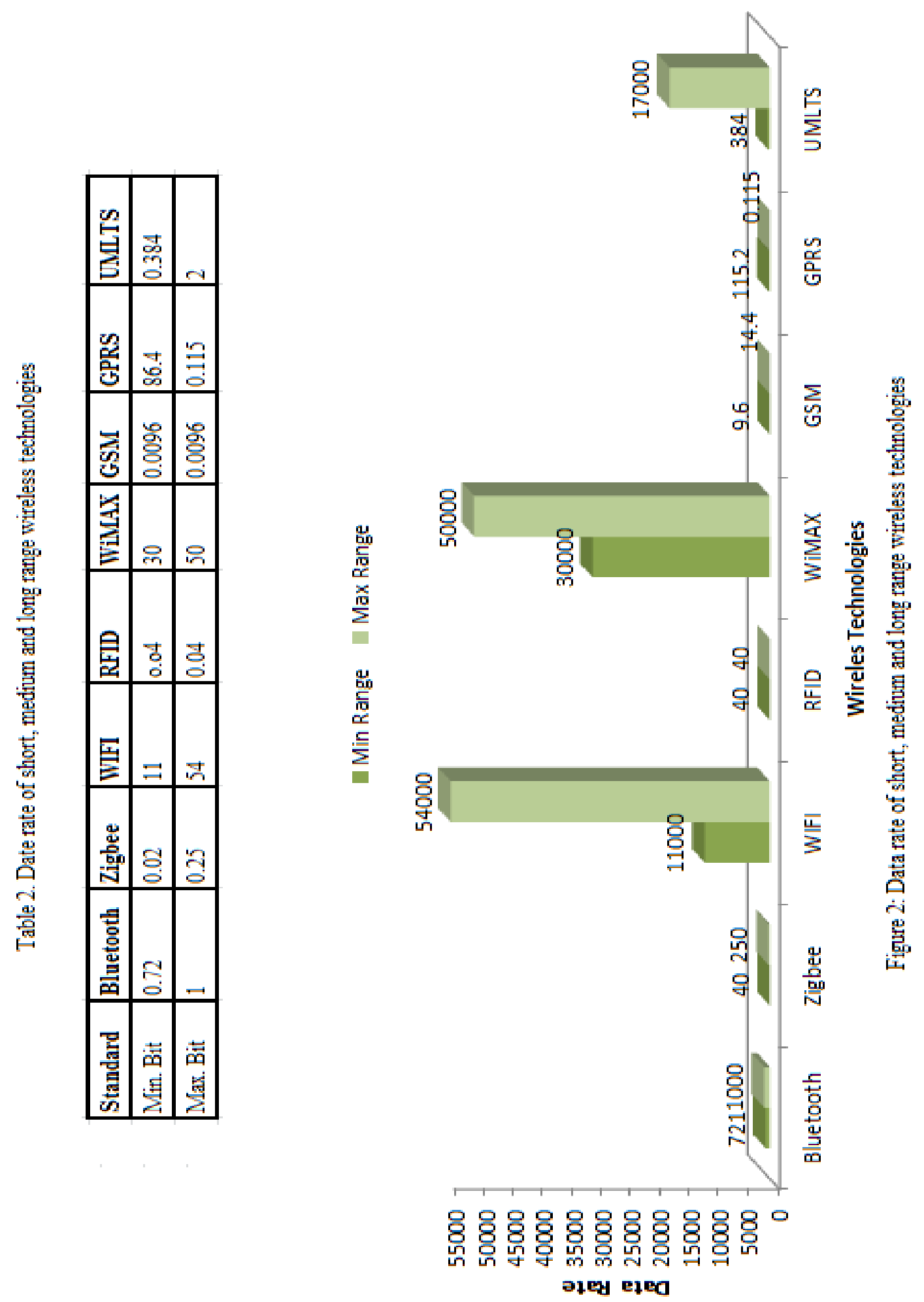
Table 3. Survey on technologies need for interfacing WSNs with cloud

\begin{tabular}{|c|c|c|c|c|c|c|c|c|}
\hline Standard & WiMax & ZigBee & Bluetooth & WiFi & RFID & GSM & GPRS & UMTS \\
\hline Technology & $\begin{array}{l}\text { Broadband } \\
\text { MAN }\end{array}$ & LR-WPAN & WPAN & WLAN & LAN & $2^{\text {nd }}$ Generation & 2.5 Generation & $3^{\text {rd }}$ Generation \\
\hline Data Rate & $\begin{array}{c}30 \mathrm{Mb} / \mathrm{s} \\
\text { To } 50 \mathrm{Mb} / \mathrm{s}\end{array}$ & $250 \mathrm{~kb} / \mathrm{s}$ & $1 \mathrm{Mb} / \mathrm{s}$ & $54 \mathrm{Mb} / \mathrm{s}$ & $40 \mathrm{~kb} / \mathrm{s}$ & $\begin{array}{c}9.6 \mathrm{~Kb} / \mathrm{s} \text { to } \\
14.4 \mathrm{~kb} / \mathrm{s}\end{array}$ & $115.2 \mathrm{~Kb} / \mathrm{s}$ & $\begin{array}{c}0.384 \mathrm{Mb} / \mathrm{s} \text { to } \\
02 \mathrm{Mb} / \mathrm{s}\end{array}$ \\
\hline $\begin{array}{l}\text { Nominal } \\
\text { Range }\end{array}$ & $\begin{array}{c}10-50 \mathrm{KM} \\
1-5 \mathrm{~m}\end{array}$ & $10-100 \mathrm{~m}$ & $10-100 \mathrm{~m}$ & $100 \mathrm{~m}$ & 1 to $10 \mathrm{~m}$ & $0.5-35 \mathrm{~km}$ & $0.5-35 \mathrm{~km}$ & $0.1-10 \mathrm{~km}$ \\
\hline $\begin{array}{c}\text { Channel } \\
\text { Bandwidth }\end{array}$ & $1.25-20 \mathrm{MHz}$ & $\begin{array}{c}0.3 / 0.6 \mathrm{MHz} \\
2 \mathrm{MHz}\end{array}$ & $1 \mathrm{MHz}$ & $22 \mathrm{MHz}$ & $200 \mathrm{KHz}$ & $200 \mathrm{KHz}$ & $200 \mathrm{KHz}$ & $5 \mathrm{MHz}$ \\
\hline $\begin{array}{c}\text { Data } \\
\text { Protection }\end{array}$ & $\begin{array}{c}\text { AES CMAc } \\
\text { MD-5 } \\
\text { HMAC }\end{array}$ & 16 bit CRC & 16-bit CRC & 32 -bit CRC & 256 & $\begin{array}{l}3 \text {-bit } \mathrm{CRC} \text { with } \\
1 / 2 \text { convolution }\end{array}$ & $\begin{array}{c}\text { 3-bit CRC } \\
\text { with } 1 / 2 \\
\text { convolution }\end{array}$ & ANSI-41,SS7 \\
\hline Nodes & 1 & $\begin{array}{l}\text { More than } \\
65000\end{array}$ & 8 & 32 & 3 or more & $\begin{array}{c}7 \text { cells/cluster } \\
9,12,13\end{array}$ & $\begin{array}{c}7 \text { cells/cluster } \\
9,12,13\end{array}$ & $1-7$ cells \\
\hline $\begin{array}{c}\text { Acquisition } \\
\text { Time of Node }\end{array}$ & $100 \mathrm{~ms}$ & $30 \mathrm{~ms}$ & $3 \mathrm{~s}$ & $2 \mathrm{~s}$ & $\begin{array}{l}\text { Depends on } \\
\text { Radio signal }\end{array}$ & $\begin{array}{l}\text { Depends on } \\
\text { GOS }\end{array}$ & $\begin{array}{l}\text { Depends on } \\
\text { GOS }\end{array}$ & $\begin{array}{l}\text { Depends on } \\
\text { GOS }\end{array}$ \\
\hline $\begin{array}{l}\text { Wake up time } \\
\text { Node }\end{array}$ & $100 \mathrm{~ms}$ & $15 \mathrm{~ms}$ & $3 \mathrm{~s}$ & $1 \mathrm{~s}$ & NA & NA & NA & NA \\
\hline Topology & $\begin{array}{l}\text { Point to } \\
\text { Multipoint, } \\
\text { Multipoint to } \\
\text { Multipoint }\end{array}$ & $\begin{array}{l}\text { Star, Mesh, } \\
\text { Cluster-tree }\end{array}$ & $\begin{array}{c}\text { Star, Piconet, } \\
\text { Scatter-net }\end{array}$ & $\begin{array}{c}\text { Star } \\
\text { Topology }\end{array}$ & $\begin{array}{l}\text { Multipoint } \\
\text { to } \\
\text { Multipoint }\end{array}$ & $\begin{array}{c}\text { Multipoint to } \\
\text { Multipoint }\end{array}$ & $\begin{array}{l}\text { Multipoint to } \\
\text { Multipoint }\end{array}$ & $\begin{array}{l}\text { Multipoint to } \\
\text { Multipoint }\end{array}$ \\
\hline $\begin{array}{l}\text { Category } \\
\text { of Power }\end{array}$ & High & Low & Low & Low & low & High & High & High \\
\hline $\begin{array}{l}\text { Consumption } \\
\text { of Power }\end{array}$ & $\begin{array}{c}100 \mathrm{~mW}-10 \mathrm{~W} \\
20-40 \mathrm{dBm}\end{array}$ & $\begin{array}{c}3.16 \mu \mathrm{W}- \\
1 \mathrm{~mW} \\
-25 \text { to } 0 \mathrm{dBm}\end{array}$ & $\begin{array}{l}1-10 \mathrm{~m} \mathrm{~W} \\
0-10 \mathrm{dBm}\end{array}$ & $\begin{array}{c}31.6-100 \mathrm{~mW} \\
15-20 \mathrm{dBm}\end{array}$ & $\begin{array}{c}0.5-2 \mathrm{w} \\
27-33 \mathrm{dBm}\end{array}$ & $\begin{array}{c}0.5-2 \mathrm{~W} \\
27-33 \mathrm{dBm}\end{array}$ & $\begin{array}{c}0.5-2 \mathrm{~W} \\
27-33 \mathrm{dBm}\end{array}$ & $\begin{array}{c}600 \mathrm{~mW} \\
27.78 \mathrm{dBm}\end{array}$ \\
\hline Range & Long & Short & Short & Middle & Middle & Long & Long & Long \\
\hline $\begin{array}{l}\text { Frequency } \\
\text { Band }\end{array}$ & $\begin{array}{l}10-66 \mathrm{GHz} \\
2-11 \mathrm{GHz}\end{array}$ & $\begin{array}{c}868 / 915 \mathrm{MHz} \\
2.4 \mathrm{GHz}\end{array}$ & $2.4 \mathrm{GHz}$ & $\begin{array}{c}2.4 \mathrm{GHz} \\
5 \mathrm{GHz}\end{array}$ & $\begin{array}{c}860 \text { to } 960 \\
\mathrm{MHz}\end{array}$ & $900-1800 \mathrm{MHz}$ & $900-1800 \mathrm{MHz}$ & $\begin{array}{l}1.92-1.98 \mathrm{GHz} \\
2.11-2.17 \mathrm{GHz}\end{array}$ \\
\hline Encryption & $\begin{array}{l}\text { 128-bit AES } \\
\text { 3-DES,EAP }\end{array}$ & $\begin{array}{l}40 \text { bit RC4 } \\
\text { block cipher }\end{array}$ & $\begin{array}{l}\text { 128- bit AES } \\
\text { block cipher }\end{array}$ & $\begin{array}{c}128 \text { bit RC4 } \\
\text { Stream cipher } \\
\text { (WEP) }\end{array}$ & $\begin{array}{l}\text { AES Read/ } \\
\text { Write } \\
\text { protection, } \\
\text { anti-cloning, } \\
\text { and no } \\
\text { encryption }\end{array}$ & $\begin{array}{l}\text { A5 and A8 } \\
\text { Algorithm }\end{array}$ & $\begin{array}{l}\text { Token based, } \\
\text { WAP, IPsec }\end{array}$ & $\begin{array}{c}\text { Token based } \\
\text { Security }\end{array}$ \\
\hline Cost & Low & Low & Low & High & High & High & High & High \\
\hline Security & Moderate & Moderate & Moderate & High & Moderate & High & High & High \\
\hline Application & $\begin{array}{l}\text { Interface with } \\
\text { internet ,IOT } \\
\text { server } \\
\text { communicatio } \\
\text {-n }\end{array}$ & $\begin{array}{l}\text { Interface with } \\
\text { internet IOT } \\
\text { server } \\
\text {, sensor } \\
\text { networks } \\
\text { building } \\
\text { automation }\end{array}$ & $\begin{array}{l}\text { Wireless } \\
\text { connectivity } \\
\text { between } \\
\text { devices like } \\
\text { phones, and } \\
\text { sets, Sensor } \\
\text { node, IOT } \\
\text { application }\end{array}$ & $\begin{array}{c}\text { Interface with } \\
\text { internet } \\
\text { IOT server } \\
\text { communicate } \\
\text {-on, } \\
\text { IP camera, } \\
\text { Gateway } \\
\text { device }\end{array}$ & $\begin{array}{l}\text { Inventory } \\
\text { access, } \\
\text { Tracking. } \\
\text { of asset and } \\
\text { item. }\end{array}$ & $\begin{array}{c}\text { Sensor } \\
\text { interface, smart } \\
\text { city automation }\end{array}$ & $\begin{array}{l}\text { Navigation, } \\
\text { traffic } \\
\text { condition, } \\
\text { Location } \\
\text { finder }\end{array}$ & $\begin{array}{l}\text { Interface with } \\
\text { internet IOT } \\
\text { server } \\
\text { communication }\end{array}$ \\
\hline
\end{tabular}

